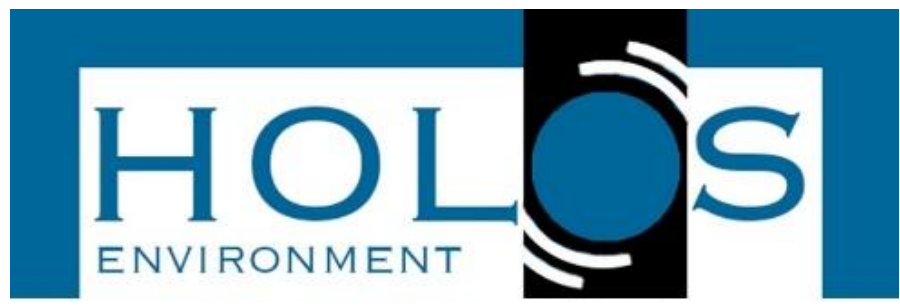

\title{
MONITORAMENTO DAS CONCENTRAÇÕES TOTAIS DE COBRE, FERRO E MANGANÊS NA DIGESTÃO ANAERÓBIA DE MELAÇO
}

\section{MONITORING OF TOTAL CONCENTRATIONS OF COPPER, IRON AND MANGANESE IN THE ANAEROBIC DIGESTION OF MOLASSES}

\author{
Camila Marques dos Reis da Silva ${ }^{1}$; Lauren Nozomi Marques Yabuki'; \\ Marcelo Loureiro Garcia ${ }^{1}$
}

Artigo recebido em: 01/03/2019 e aceito para publicação em: 06/05/2019.

DOI: http://dx.doi.org/10.14295/holos.v19i2.12332

Resumo: Atualmente, onde o uso dos combustíveis fósseis e a emissão excessiva dos gases do efeito estufa impactam diretamente a qualidade do meio ambiente, a busca por fontes alternativas sustentáveis que supram o aumento da demanda energética mundial é imprescindível. Diante desse cenário, uma solução é o uso de águas residuárias para produção de bioenergia, através de biorrefinarias que, por meio de processos biológicos anaeróbios, digerem a matéria orgânica presente nas águas residuárias e geram o biogás. A produção de biogás ou a eficiência do processo pode ser influenciada pela quantidade de elementos-traço presente na água residuária. O objetivo deste trabalho foi monitorar as concentrações totais dos elementos-traços cobre, ferro e manganês na digestão anaeróbia do melaço para tentar estabelecer a influência dos metais sobre a produção de biogás a partir do tratamento do melaço, a fim de obter uma maximização da produção de energia na forma de biogás, sendo de grande importância e aplicabilidade para minimizar os impactos ambientais. Para o melaço, não foi verificada uma correlação de influência para as faixas de concentração analisadas do cobre $(36,78$ a 449,38 $\mu \mathrm{g}$. $\left.\mathrm{L}^{-1}\right)$, ferro $\left(154,61\right.$ a $\left.2160,31 \mu \mathrm{g} \cdot \mathrm{L}^{-1}\right)$ e manganês $\left(25,79\right.$ a $\left.391,83 \mu \mathrm{g} \cdot \mathrm{L}^{-1}\right)$, pois essas faixas não afetaram o desempenho do biorreator.

Palavras-chave: Melaço. Biogás. Elementos-traço. Reatores anaeróbios.

Abstract: Nowadays, where the use of fossil fuels and the excessive emission of greenhouse gases directly affect the quality of the environment, the search for sustainable alternative sources that meet the increase of the world energy demand is indispensable. In this scenario, one solution is the use of wastewater for bioenergy production, through biorefineries that, through anaerobic biological processes, digest the organic matter present in the wastewater and generate biogas. Biogas production or process efficiency can be influenced by the amount of trace elements present in the wastewater. The objective of this work was to monitor the total concentrations of copper, iron and manganese trace elements in the anaerobic digestion of molasses to try to establish the influence of the metals on the biogas production from the treatment of molasses, in order to obtain a maximization of the energy production in the form of biogas, being of great importance and applicability to minimize environmental impacts. For molasses, a correlation of influence was not observed for the analyzed concentration ranges of copper (36.78 to $449.38 \mu \mathrm{g} . \mathrm{L}^{-1}$ ), iron (154.61 to $2160.31 \mu \mathrm{g} . \mathrm{L}^{-1}$ ) and manganese $\left(25,79\right.$ to $\left.391,83 \mu \mathrm{g} . \mathrm{L}^{-1}\right)$, because these ranges did not affect the performance of the bioreactor.

Palavras-chave: Molasses. Biogas. Trace elements. Anaerobic reactors.

\footnotetext{
1 Universidade Estadual Paulista "Júlio de Mesquita Filho", campus Rio Claro, SP. E-mails: (camila.reis.silva@gmail.com, lauren.yabuki@gmail.com, mlgarcia@rc.unesp.br)
} 


\section{INTRODUÇÃO}

A poluição ambiental é um problema crescente com impacto direto na qualidade de vida da população, pois existe um enorme desequilíbrio entre a quantidade de resíduos gerados pela sociedade e a capacidade de ciclagem do meio. O consumo de combustíveis fósseis é responsável por grande parte da poluição ambiental e desde o século passado a humanidade vem sofrendo os efeitos negativos do seu uso como, por exemplo, as mudanças climáticas associadas ao aumento da concentração de dióxido de carbono na atmosfera terrestre (NASA, 2017; IPCC, 2014). Neste cenário, uma alternativa à dependência dos combustíveis fósseis do modelo econômico atual e à crescente demanda energética é a produção de energia a partir da biomassa (IEAb, 2016).

O uso de biomassa como fonte de energia renovável está diretamente relacionado com o ciclo do carbono, pois reduz a emissão de gases do efeito estufa por meio do sequestro de carbono pelas culturas e da substituição dos combustíveis fósseis pelos biocombustíveis (FUESS e GARCIA, 2014). No Brasil, a produção de biocombustível a partir da cana-de-açúcar desenvolveu-se de maneira impressionante e em 2015 o estado de São Paulo produziu 13,7 bilhões de litros de etanol a partir da canade-açúcar e, para cada litro de etanol produzido, gerou 11,8 litros de vinhaça (IEAa, 2016; TORQUATO e JESUS, 2015). Assim, mesmo com as vantagens do uso do etanol, a enorme quantidade de vinhaça produzida pode contribuir para o aumento da poluição.

Inserida no setor sucroalcooleiro, a produção de açúcar também gera um resíduo orgânico, o melaço, que pode ser utilizado no tratamento anaeróbio e geração de biogás (PUGLIANO et al., 2014; JANKE et al., 2015). O melaço de cana-de-açúcar, líquido viscoso e com alto teor de açúcares, é um subproduto da etapa de centrifugação no processo de fabricação de açúcar cristalizado ou melado ou da refinação do açúcar bruto (DETMAN et al., 2017, ANVISA, 1978). No Brasil, são produzidos cerca de 50 quilos de melaço por tonelada de cana-de-açúcar processada, contendo altos níveis de DBO (Demanda Bioquímica de Oxigênio) e DQO (Demanda Química de Oxigênio) (EMBRAPA, 2017; LI et al., 2007; WILKIE et al., 2000).

O tratamento das águas residuárias, feito com o objetivo de remover a matéria orgânica, nutrientes, patógenos e outras substâncias, é importante para evitar a 
poluição do solo e das águas subterrâneas e superficiais, danos aos ecossistemas e a dispersão de doenças (VON SPERLING, 2005). O processo de tratamento em reatores anaeróbios tem a vantagem das bactérias anaeróbias consumirem a matéria orgânica presente na vinhaça e no melaço e gerar bioenergia, o que permite a lucratividade em uma biorrefinaria (RAJESHWARI et al., 2000; LI et al., 2007).

Biorrefinarias são centrais de conversão de matéria orgânica em biocombustíveis que utilizam diversos tipos de biomassas para gerar energia, resultando em benefícios econômicos e ambientais (EMBRAPA, 2011; MORAES, 2014). O conceito de biorrefinaria pode ser aplicado no tratamento biológico da vinhaça e do melaço para geração de biogás. $O$ tratamento anaeróbio da vinhaça apresenta baixa produção de lodo e conversão de aproximadamente $50 \%$ da DQO total da vinhaça em biogás, e do melaço proporciona remoção de 13\% da DQO do melaço (PUGLIANO et al., 2014; HAN et al., 2012). A velocidade de biodegradação anaeróbia no tratamento está relacionada com a concentração de elementos traço que estimulam a atividade metanogênica e, quando há deficiência dos metais, o crescimento dos micro-organismos no reator é limitado, podendo levar à instabilidade ou falha do processo (JANKE et al., 2016; FERMOSO et al., 2008, FERMOSO et al., 2009; THANH et al., 2016). Portanto, o estudo da influência dos elementos-traço da geração de biogás é muito importante.

Em especial, foram escolhidos o cobre, o ferro e o manganês, para realização deste estudo, pois, depois dos macronutrientes, são estes metais inorgânicos que estão presentes em maior concentração nos solos tropicais brasileiros (COSTA et al., 2016) e, consequentemente, na vinhaça e no melaço (MUTTON, ROSSETTO, MUTTON, 2010; VALDUGA et al., 2007).

O objetivo deste trabalho foi monitorar as concentrações totais dos elementostraços cobre, ferro e manganês na digestão anaeróbia do melaço para tentar estabelecer a influência dos metais sobre a produção de biogás a partir do tratamento anaeróbio do melaço, de modo que favoreça a eficiência da produção de biogás contribuindo para o reequilíbrio dos ciclos de matéria e energia.

\section{MATERIAL E MÉTODOS}

Primeiramente, a concentração de metais traços cobre, ferro e manganês presentes no melaço (resíduo da produção de açúcar) foi determinada nas correntes de entrada e saída, de um reator anaeróbio em operação. Em seguida, foi comparada a 
respectiva concentração dos elementos-traço cobre, ferro e manganês com a remoção de matéria orgânica (DQO) e a produção de biogás no processo anaeróbio do reator em questão.

A operação e o monitoramento do reator anaeróbio foram realizadas no Laboratório de Processos Biológicos (LPB/EES/USP-São Carlos). As amostras de melaço foram obtidas do reator metanogênico de leito fixo (ASTBR), operado em condições termofílicas (à temperatura de $55^{\circ} \mathrm{C}$ ), com carga orgânica volumétrica (COV) de entrada variando de 2,5 a $10 \mathrm{~g} \cdot \mathrm{L}^{-1} \cdot \mathrm{d}^{-1}$ e adição de bicarbonato $\left(\mathrm{NaHCO}_{3}\right)$, solução de nutrientes e solução de vitaminas durante a sua operação. A alimentação do reator foi realizada com diluição de $12 \mathrm{~g} \cdot \mathrm{L}^{-1}$ de melaço em água de abastecimento (OLIVEIRA, 2018).

O monitoramento foi realizado por meio de amostras da entrada e saída para verificação dos parâmetros de $\mathrm{pH}$, alcalinidade seguindo o método de Dilallo e Albertson (1961); DQO, Sólidos Suspensos Voláteis (SSV), Sólidos Suspensos Totais (SST) segundo a metodologia do Standard Methods for the Examination of Water and Wastewater (APHA, 2005) e carboidratos totais segundo Dubois et al. (1956) e Blundi e Gadêlha (2001). Os ácidos orgânicos voláteis - AVT (acético - HAc, propiônico - HPr, butírico- HBu e isobutírico- Hlbu) foram quantificados em cromatógrafo gasoso modelo GC 2010 (Shimadzu $^{\circledR}$ ), equipado com detector de ionização de chama (FID) e coluna HP-INNOWAX (30 mm de comprimento; 0,25 mm de diâmetro interno e 0,25 $\mu \mathrm{m}$ de espessura de filme) (OLIVEIRA, 2018).

No reator, foi monitorada continuamente a vazão de biogás com auxílio de um gasômetro Ritter® e a análise da composição do biogás - hidrogênio $\left(\mathrm{H}_{2}\right)$, nitrogênio $\left(\mathrm{N}_{2}\right)$, metano $\left(\mathrm{CH}_{4}\right)$, e gás carbônico $\left(\mathrm{CO}_{2}\right)$ - foi realizada utilizando um cromatógrafo gasoso GC 2010 (Shimadzu®), equipado com detector de condutividade térmica, com coluna Carboxen $\AA 1010$ Plot $30 \mathrm{~m} \times$ 0,53 mm e tendo como gás de arraste o argônio (PERNA et al., 2013).

A espectroscopia de emissão óptica com plasma indutivamente acoplado (ICP OES) foi a técnica de análise dos elementos-traço utilizada após prévia digestão ácida em sistema aberto por bloco aquecedor (DIMPE et al., 2014). As amostras foram prédigeridas (overnight) com tubos digestores de vidro borossilicato com $10 \mathrm{~mL}$ de cada amostra e $3 \mathrm{~mL}$ de água régia $\left(\mathrm{HCl} / \mathrm{HNO}_{3}\right.$, proporção 3:1, segundo metodologia descrita por EHS, 2017; STANDARD, 2000). Posteriormente, foram aquecidas sobre o bloco aquecedor (Tecnal TE40-05) a $150^{\circ} \mathrm{C}$ durante aproximadamente 4 horas. Para 
validação do método, as amostras foram digeridas em duplicata e, juntamente com as amostras, foram digeridas também: i) duplicatas do branco do método (10 $\mathrm{mL}$ de água ultra-pura com $3 \mathrm{~mL}$ de água régia processada exatamente como a amostra, incluindo exposição a todo equipamento, vidraria, procedimentos e reagentes), ii) o branco fortificado (branco do método contendo todos os reagentes como as amostras, no qual uma concentração conhecida dos analitos é adicionada) e iii) a amostra fortificada (10 $\mathrm{mL}$ de uma amostra na qual, antes do seu processamento, são adicionadas quantidades conhecidas dos analitos de interesse) (PINHEIRO, 2014; KRUG e ROCHA, 2016; PEREIRA et al., 2018).

A digestão das amostras e as análises dos elementares foram realizadas no Instituto de Geociências e Ciências Exatas (IGCE/UNESP, Rio Claro-SP). Durante a digestão agitaram-se os tubos de vidro para observar a evolução dos estágios da digestão ácida, o branqueamento indicou o consumo da matéria orgânica e ocorreu redução do volume nos tubos de vidro (Figura 1). Após a digestão, o conteúdo dos tubos de vidro foi transferido para tubos Falcon $(50 \mathrm{~mL})$. Em seguida, foram feitas as análises das soluções aquosas utilizando um espectrômetro ICP OES (iCAP 6000 Series, Thermo Scientific, EUA) para determinar a concentração total de cada metal presente no material analisado. Os resultados das concentrações obtidos pelo ICP OES foram analisados estatística e graficamente.

Figura 1 - Amostra de melaço efluente antes (à esquerda) e depois (à direita) da digestão

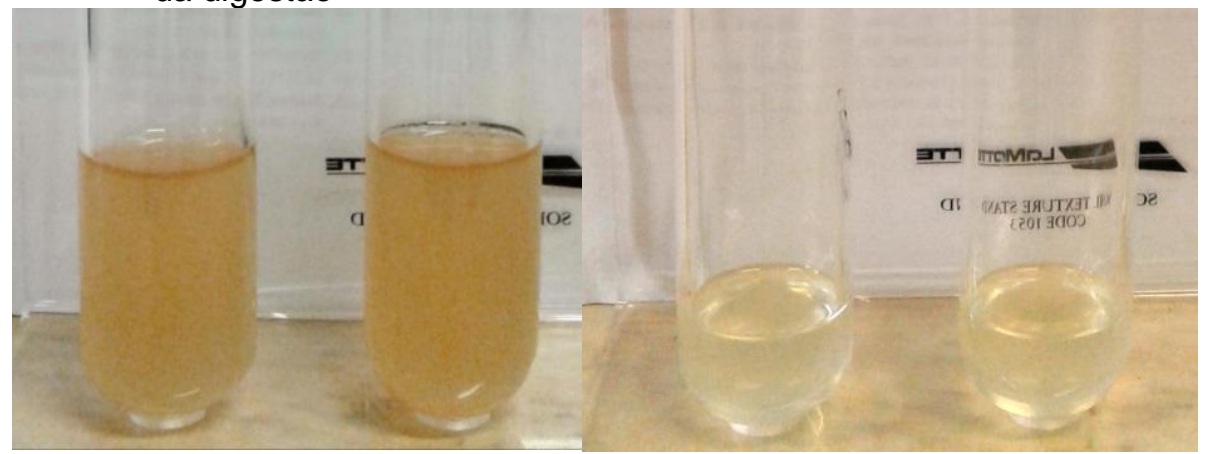

Fonte: Os autores (2019)

\subsection{Cálculos}

Quantificando-se: o rendimento de biogás $(R)$ obtido dos processos de digestão anaeróbia do melaço em $\mathrm{mLCH}_{4} \cdot \mathrm{gDQO}^{-1}$ e a carga orgânica volumétrica (COV) de DQO de entrada e de saída em gDQO. $\mathrm{L}^{-1} \cdot \mathrm{d}^{-1}$, que indiretamente indica a 
concentração de DQO, calculou-se a eficiência de remoção de DQO (\%) por meio da equação (1) e a produção volumétrica de metano (PVM) através da equação (2) para relacionar com a concentração dos elementos-traço (Tabela 1).

$$
\varepsilon=\frac{[D Q O]_{\text {entrada }}-[D Q O]_{\text {saída }}}{[D Q O]_{\text {entrada }}} 100 \%
$$

sendo $\varepsilon$ a eficiência de remoção de DQO (\%) (VON SPERLING, 1996, p. 49).

$$
P V M=R \cdot \operatorname{COV}_{\text {entrada }} \cdot \varepsilon
$$

sendo PVM a produção volumétrica de metano em $\mathrm{mLCH}_{4} \cdot \mathrm{L}^{-1} \cdot \mathrm{d}^{-1}$ (FUESS, 2013). Para realizar o teste de recuperação dos metais das amostras digeridas utilizou-se a equação (3).

$$
T R=\frac{[A p]-[A]}{[A]} \cdot 100 \%
$$

sendo $\boldsymbol{T} \boldsymbol{R}$ a recuperação dos metais (\%), $[\boldsymbol{A p}]$ a concentração de metais nas duplicatas da amostra de melaço com padrão multielementar (250 ppb) sendo digeridas $\left(\mu \mathrm{g} . \mathrm{L}^{-1}\right)$ e $[\boldsymbol{A}]$ o valor real, ou seja, a concentração de metais nas duplicatas da amostra de melaço (sem padrão multielementar) sendo digeridas ( $\mu \mathrm{g} . \mathrm{L}^{-1}$ ) (BRITO, 2003).

\section{RESULTADOS E DISCUSSÃO}

O desempenho do tratamento anaeróbio das amostras de melaço de cana-deaçúcar avaliadas neste trabalho é mostrado pela $P V M$ e eficiência de remoção de DQO (Tabela 1). Particularmente, a PVM, calculada com base nos dados referentes à eficiência de remoção de DQO, ao rendimento de biogás e à COV de DQO de entrada (seção 2.1), apresentou valores entre 827,65 e $2917,28 \mathrm{mLCH} 4 \cdot \mathrm{L}^{-1} \cdot \mathrm{d}^{-1}$, tendo como PVM média o valor de 2166,10 $\pm 517 \mathrm{mLCH}_{4} \cdot \mathrm{L}^{-1} \cdot \mathrm{d}^{-1}$ (Tabela 2).

A remoção de DQO nas amostras analisadas de melaço se mostrou majoritariamente eficiente, obtendo resultados acima de 78,50\% em 14 das 15 amostras analisadas (Tabela 1) e tendo como valor médio $82 \pm 15 \%$ (Tabela 2 ). Apenas a amostra 
15 obteve uma eficiência de 30,30\% de remoção de DQO (esta amostra também apresenta o menor valor de $P V M$ ), devido à mudança na operação no reator metanogênico, retirando o alcalinizante $\mathrm{NaHCO}_{3}$ e acidificando o sistema na fase de coleta da amostra. A acidificação do sistema retira as condições ideais para as arqueias metanogênicas sobreviverem, assim, aos poucos a produção de $\mathrm{CH}_{4}$ reduziu até cessar por completo. A amostra 15 também apresenta os menores valores de concentração para ferro e manganês, para cobre a concentração não pôde ser quantificada, pois estava abaixo do LD do espectrômetro ICP-OES.

As maiores concentrações de cobre, ferro e manganês na corrente de entrada de melaço, amostras 10, 12 e 14 (Tabela 1), estão relacionadas às grandes eficiências de remoção de DQO, respectivamente, 89,84\%, 87,42\% e 89,30\%, quando comparadas a média de eficiência de remoção. Também nota-se altas $P V M$ relacionadas às amostras 10, 12 e 14, em ordem, 2225,61, 2218,64 e 2243,58 mL.CH4. $\mathrm{L}^{-1} \cdot \mathrm{d}^{-1}$.

Tabela 1- Resultados das análises das amostras de melaço de cana-de-açúcar

\begin{tabular}{|c|c|c|c|c|c|c|c|c|c|c|}
\hline \multirow{2}{*}{ Amostra } & \multicolumn{3}{|c|}{$\begin{array}{l}\text { Concentração de } \\
\text { entrada }\left(\mu \mathrm{g} . \mathrm{L}^{-1}\right)\end{array}$} & \multicolumn{3}{|c|}{$\begin{array}{c}\text { Concentração de } \\
\text { saída }\left(\mu g . L^{-1}\right)\end{array}$} & \multirow{2}{*}{$\begin{array}{l}\text { Cov entrada } \\
\left(g \cdot L^{-1} \cdot d^{-1}\right)\end{array}$} & \multirow{2}{*}{$\begin{array}{c}\text { Cov saída } \\
\left(g \cdot L^{-1} \cdot d^{-1}\right)\end{array}$} & \multirow{2}{*}{$\begin{array}{c}\text { PVM } \\
\left(\mathrm{mLCH} 4 . \mathrm{L}^{-1} \cdot \mathrm{d}^{-1}\right)\end{array}$} & \multirow{2}{*}{$\begin{array}{c}\varepsilon \\
(\%)\end{array}$} \\
\hline & $\mathrm{Cu}$ & $\mathrm{Fe}$ & $M n$ & $\mathrm{Cu}$ & $\mathrm{Fe}$ & Mn & & & & \\
\hline 1 & 157,62 & 1249,91 & 363,43 & 48,70 & 701,36 & 190,50 & 9,76 & 2,10 & 1964,89 & 78,50 \\
\hline 2 & 143,66 & 796,99 & 305,52 & 33,20 & 433,25 & 119,05 & 10,34 & 1,56 & 1642,49 & 84,90 \\
\hline 3 & 36,78 & 968,36 & 288,28 & 238,67 & 1364,21 & 139,36 & 11,03 & 1,39 & 2487,47 & 87,40 \\
\hline 4 & 144,21 & 1457,84 & 212,37 & 153,63 & 681,92 & 207,47 & 11,52 & 1,56 & 2157,17 & 80,00 \\
\hline 5 & 56,64 & 1377,32 & 213,91 & 111,03 & 689,15 & 142,74 & 9,87 & 1,56 & 2269,74 & 84,17 \\
\hline 6 & 41,73 & 928,45 & 266,37 & 36,14 & 636,50 & 142,25 & 8,41 & 1,45 & 2917,28 & 82,80 \\
\hline 7 & 152,35 & 969,15 & 200,34 & 131,89 & 666,43 & 95,79 & 9,21 & 1,26 & 2309,01 & 86,34 \\
\hline 8 & 142,46 & 1104,01 & 391,83 & 90,45 & 367,05 & 60,27 & 10,41 & 1,34 & 2356,20 & 87,17 \\
\hline 9 & 160,48 & 1623,85 & 298,70 & 91,52 & 730,48 & 91,72 & 9,16 & 1,18 & 1567,58 & 87,08 \\
\hline 10 & 449,38 & 1966,01 & 357,93 & 516,87 & 799,98 & 81,54 & 9,87 & 1,00 & 2225,61 & 89,84 \\
\hline 11 & 141,42 & 1668,59 & 305,83 & 468,50 & 1865,81 & 131,33 & 8,42 & 1,01 & 2482,28 & 88,02 \\
\hline 12 & 306,19 & 2016,67 & 346,14 & 153,38 & 723,22 & 62,47 & 9,23 & 1,16 & 2218,64 & 87,42 \\
\hline 13 & $<L D$ * & 172,56 & 26,29 & $<L D$ & 206,35 & 8,00 & 9,56 & 1,04 & 2821,90 & 89,16 \\
\hline 14 & 449,02 & 2160,31 & 365,84 & 535,74 & 1330,27 & 82,043 & 8,28 & 0,89 & 2243,58 & 89,30 \\
\hline 15 & $<L D$ * & 154,61 & 25,79 & - & - & - & 9,60 & 6,69 & 827,65 & 30,30 \\
\hline
\end{tabular}


A concentração de entrada de cada metal mostrou-se, na maioria das amostras, maior que a concentração de saída (Figura 2 e Tabela 1), com eficiências médias de remoção de cobre, ferro e manganês respectivamente iguais a 43,17 $\pm 25 \%, 49 \pm$ $12 \%$ e $58 \pm 22 \%$. Porém, em algumas amostras, a concentração de saída foi maior que a de entrada, indicando que após algum tempo de operação o reator pode acumular metais no seu interior liberando-os em um tempo subsequente durante a operação.

Figura 2 - Comparação entre a concentração de entrada (ロ) e de saída ( $\square$ ) dos metais nas amostras analisadas, cada amostra corresponde a uma linha da Tabela 1
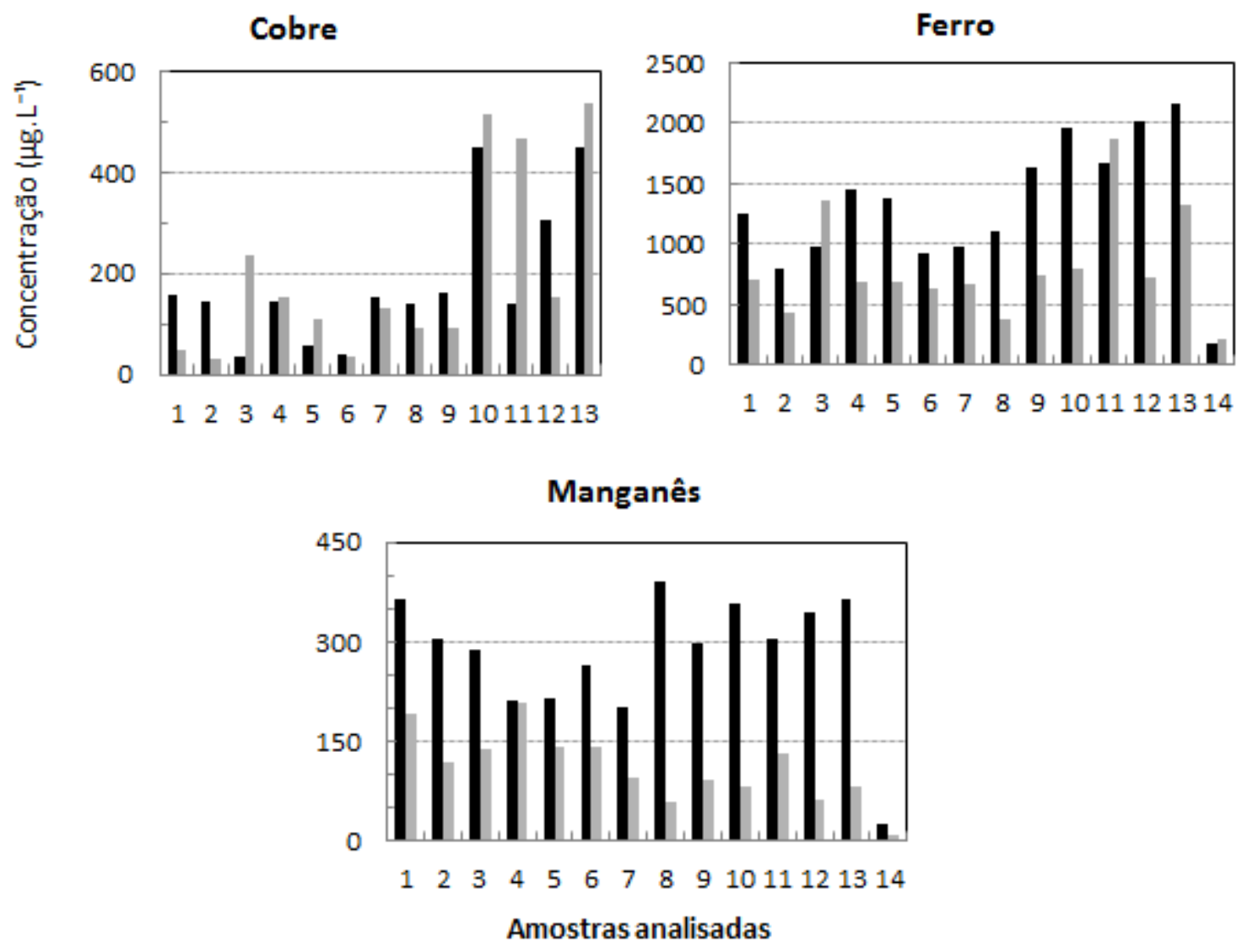

A PVM $\left(\mathrm{CH}_{4}\right)$ e a eficiência de remoção de DQO podem estar associadas com a concentração dos metais no reator. Por esta razão, os dados de concentração de cada metal na corrente de entrada (amostra de melaço afluente no reator) foram relacionados com a PVM e a eficiência de remoção de DQO em um gráfico (Figuras 3, 4 e 5).

O monitoramento dos metais-traço nas amostras de melaço afluentes no biorreator permite observar que os valores de concentração de cobre variaram de 36,78 
a 449,38 $\mu \mathrm{g} \cdot \mathrm{L}^{-1}$ (Figura 3), com concentração média igual a 183,23 $\pm 136,24 \mu \mathrm{g} \cdot \mathrm{L}^{-1}$ (Tabelas 1 e 2). Para o ferro, os valores de concentração analisados variaram de

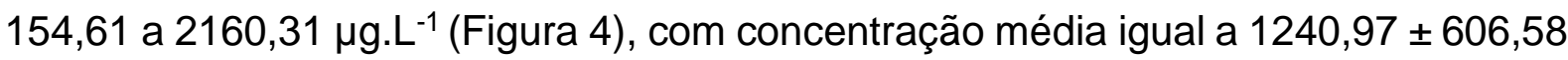
$\mu \mathrm{g} . \mathrm{L}^{-1}$ (Tabelas 1 e 2). O manganês apresentou valores de concentração variando de 25,79 a 391,83 $\mu \mathrm{g} . \mathrm{L}^{-1}$ (Figura 5), com concentração média igual a 264,57 $\pm 113,36$ $\mu \mathrm{g} \cdot \mathrm{L}^{-1}$ (Tabelas 1 e 2 ).

Figura 3 - Concentração de entrada de cobre relacionada com a produção volumétrica de metano $(\boldsymbol{\square})$ e a eficiência de remoção de DQO (ロ).

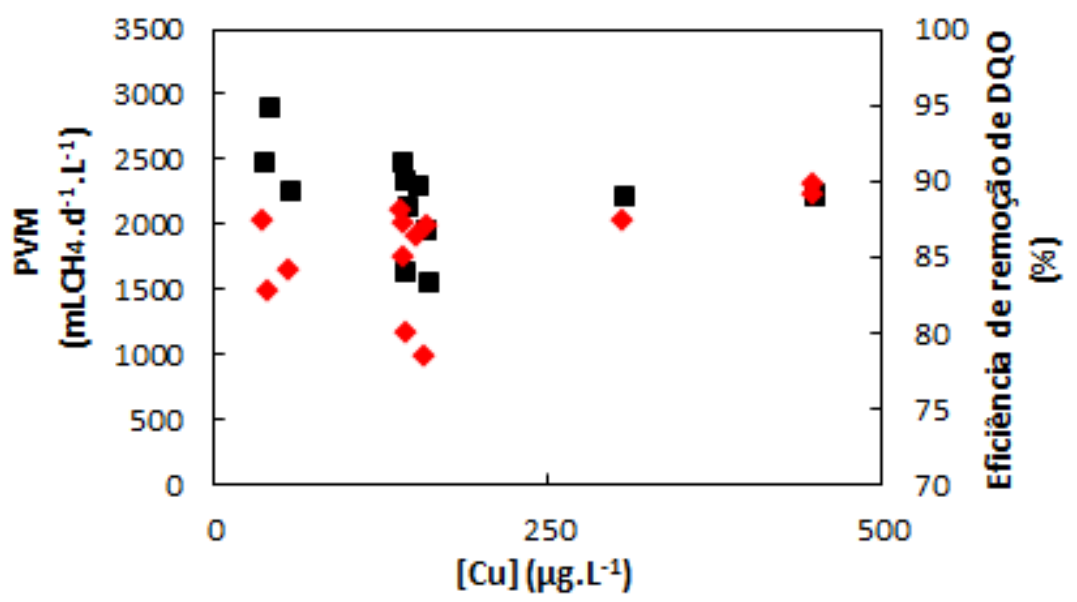

Figura 4 - Concentração de entrada de ferro relacionada com a produção volumétrica de metano (অ) e a eficiência de remoção de DQO (ロ).

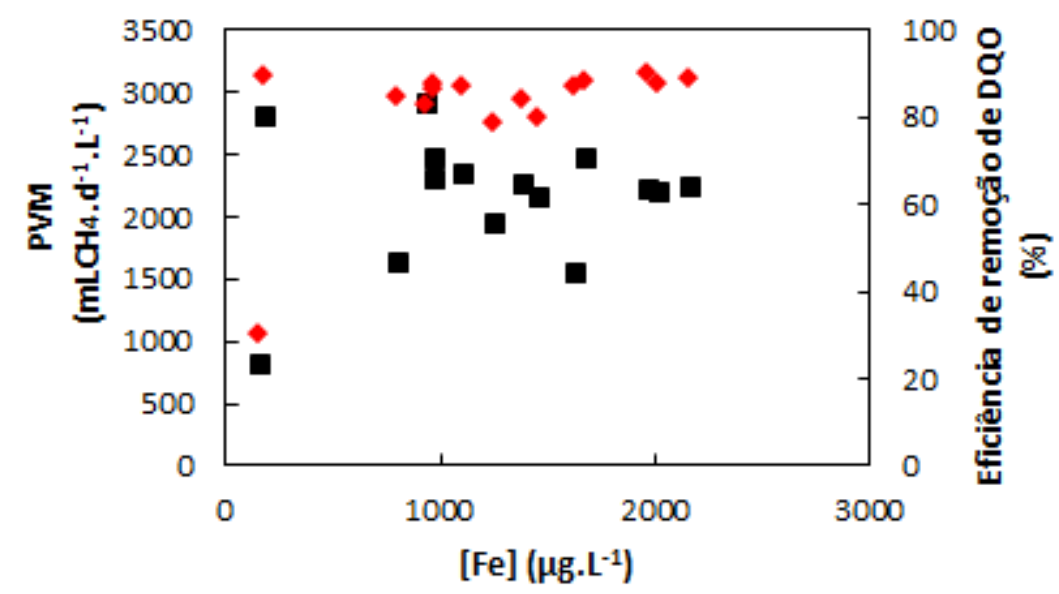


Figura 5 - Concentração de entrada de manganês relacionada com a produção volumétrica de metano (ש) e a eficiência de remoção de DQO (ロ)

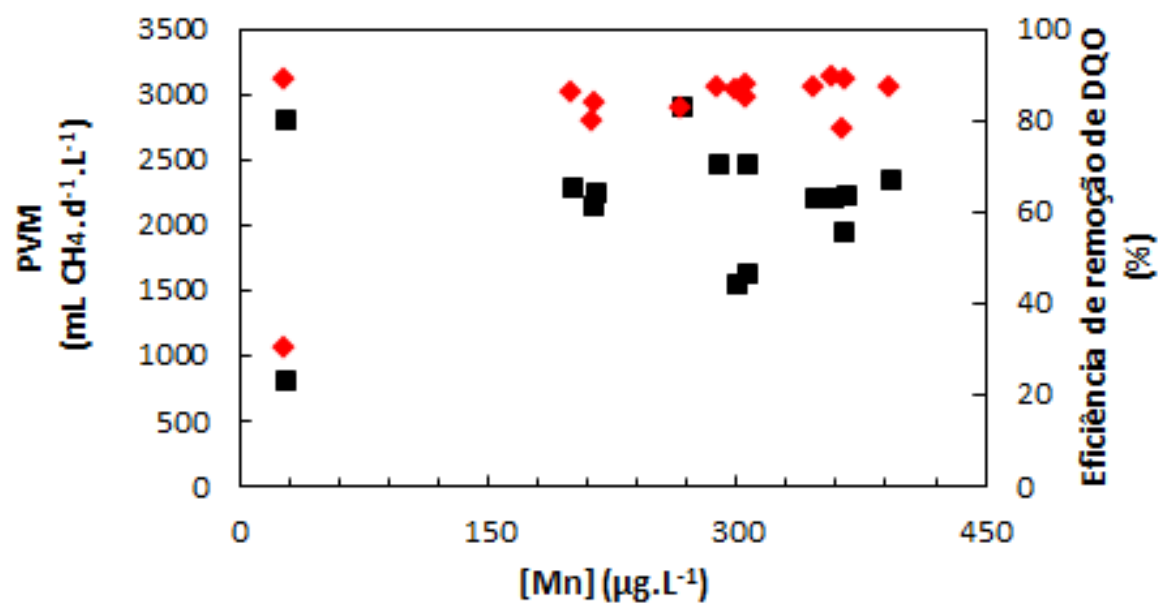

As concentrações de cobre nas correntes afluentes até valores de 449,38 $\mu$ g.L ${ }^{1}$, de ferro até $1240,97 \mu \mathrm{g} \cdot \mathrm{L}^{-1}$ e de manganês até $391,83 \mu \mathrm{g} \cdot \mathrm{L}^{-1}$ não causaram uma redução no desempenho do biorreator (Figuras 3, 4 e 5), não exercendo um efeito de inibição na produção de metano ou restringindo a eficiência de remoção de DQO no biorreator. Portanto, as faixas de concentração de cobre, ferro e manganês nas amostras avaliadas de melaço não têm efeito significativo no processo biológico de digestão dentro do reator anaeróbio. Dessa maneira, não foi verificada uma correlação de influência das faixas de concentração dos metais e a eficiência de remoção de matéria orgânica e a PVM.

A distribuição dos dados de concentração de entrada dos elementos traço cobre, ferro e manganês apresentaram grande amplitude (maior valor - menor valor de concentração), ou seja, grande variação na distribuição dos dados de concentração analisados, sendo o ferro o analito com maior variação (Figura 6 e Tabela 2). Por exemplo, os valores de concentração de entrada do ferro possuem uma amplitude de $2005,70 \mu \mathrm{g} \cdot \mathrm{L}^{-1}$, do cobre $412,61 \mu \mathrm{g} \cdot \mathrm{L}^{-1}$ e do manganês apresentou uma amplitude de $366,05 \mu \mathrm{g} \cdot \mathrm{L}^{-1}$.

É possível observar também uma grande variação de concentração dos metais comparada à grande variação dos valores de PVM, amplitude igual a 2089,63 $\mathrm{mLCH}_{4} \cdot \mathrm{L}^{-1} \cdot \mathrm{d}^{-1}$ (Tabela 2). Para a eficiência de remoção há uma amplitude de 59,54\%, devido a um único dado de eficiência igual a 30,30\% (valor mínimo), os outros valores variam entre 89,84 e $78,50 \%$. 
Os box-plots da Figura 6 apresentaram uma distribuição assimétrica positiva para o cobre e o ferro, assim, a mediana (valor que divide o conjunto de dados) das concentrações de entrada de cobre e do ferro está mais próxima do primeiro quartil (Q1). Dessa forma, os valores de concentração de entrada de cobre e ferro entre a mediana e o Q1 são mais comuns de ocorrer do que os acima. Para os valores de concentração de entrada de manganês o inverso ocorre: a mediana está mais próxima do terceiro quartil.

Tabela 2 - Tratamento estatístico dos dados experimentais obtidos para o melaço

\begin{tabular}{|c|c|c|c|c|c|c|c|c|}
\hline & \multicolumn{3}{|c|}{$\begin{array}{c}\text { Concentração de entrada } \\
\left(\mu \mathrm{g} \cdot \mathrm{L}^{-1}\right)\end{array}$} & \multicolumn{3}{|c|}{$\begin{array}{c}\text { Concentração de saída } \\
\left(\mu \mathrm{g} \cdot \mathrm{L}^{-1}\right)\end{array}$} & \multirow[t]{2}{*}{$\begin{array}{c}P V M \\
\left(\mathrm{mLCH}_{4} \cdot \mathrm{L}^{-1} \cdot \mathrm{d}^{-1}\right)\end{array}$} & \multirow[t]{2}{*}{$\begin{aligned} \varepsilon \\
(\%)\end{aligned}$} \\
\hline & $\mathrm{Cu}$ & $\mathrm{Fe}$ & $M n$ & $\mathrm{Cu}$ & $\mathrm{Fe}$ & Mn & & \\
\hline Máximo & 449,38 & 2160,31 & 391,83 & 535,74 & 1865,81 & 207,47 & 2917,28 & 89,84 \\
\hline Q3 & 233,33 & 1668,59 & 357,93 & 353,58 & 932,55 & 142,38 & 2482,28 & 88,30 \\
\hline Média & 183,23 & 1240,97 & 264,57 & 200,75 & 799,71 & 111,04 & 2166,10 & 82,42 \\
\hline Mediana & 144,21 & 1249,91 & 298,70 & 131,89 & 695,26 & 107,42 & 2243,58 & 87,12 \\
\hline Q1 & 99,03 & 928,45 & 212,37 & 69,57 & 585,68 & 76,77 & 1964,89 & 83,83 \\
\hline Mínimo & 36,78 & 154,61 & 25,79 & 33,20 & 206,35 & 8,00 & 827,65 & 30,30 \\
\hline DP & 136,24 & 606,58 & 113,36 & 183,69 & 438,63 & 53,16 & 516,97 & 14,72 \\
\hline Amplitude & 412,61 & 2005,70 & 366,05 & 502,55 & 1659,47 & 199,47 & 2089,63 & 59,54 \\
\hline
\end{tabular}

Figura 6 - Box plot da concentração de entrada dos elementos-traço. $\square$ Q1 e $\square$ Q3.

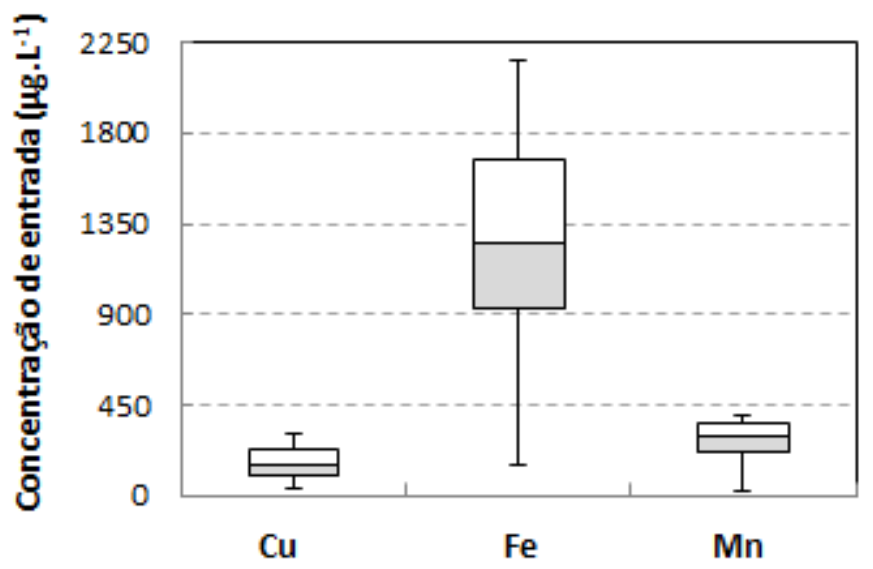

Como desenvolvimentos futuros deste trabalho, pretende-se analisar outras 
águas residuárias, com atenção especial para a vinhaça devido a sua complexidade e a sua maior importância ambiental, uma vez que a vinhaça pode causar maiores impactos ambientais que o melaço (FUESS, GARCIA, 2012).

\section{CONCLUSÕES}

Diante do que foi exposto, pode-se concluir que as faixas de concentração de cobre, ferro e manganês presentes nas amostras de melaço analisadas não causaram uma redução no desempenho do biorreator, não exercendo um efeito de inibição na produção de metano ou restringindo a eficiência de remoção de DQO no biorreator. Portanto, as concentrações dos metais analisadas para o melaço não têm efeito significativo no processo biológico de digestão dentro do reator anaeróbio, dessa maneira, não foi verificada uma correlação de influência entre as faixas de concentração dos metais e a eficiência de remoção de matéria orgânica e a PVM.

\section{AGRADECIMENTOS}

Os autores agradecem à Fundação de Amparo à Pesquisa do Estado de São Paulo (FAPESP, Processo: 2017/22108-9) pelo financiamento.

\section{REFERÊNCIAS}

ANVISA. Agência Nacional de Vigilância Sanitária. Resolução da Comissão Nacional de Normas e Padrões para Alimentos - Gerência Geral Alimentos ํำ12, 1978. Disponível em: $<$ https://sogi8.sogi.com.br/Arquivo/Modulo113.MRID109/Registro4760/documento\%201.pdf> . Acesso em 20 out. 2017.

APHA. Standard Methods for the Examination of Water and Wastewater. 21st Edition, American Public Health Association, American Water Works Association, Water Environment Federation, Washington DC, USA, 2005.

BLUNDI, C.E., GADÊLHA, R.F. Metodologia para determinação de matéria orgânica específica em águas residuárias. Pós-tratamento de efluentes de reatores anaeróbios: metodologias, v. 2, Belo Horizonte: FINEP, Cap. 1, p. 9-17, 2001.

BRITO, N.M.; AMARANTE JUNIOR, O.P.; POLESE, L.; RIBEIRO, M.L. Validação de métodos

analíticos: estratégia e discussão. Pesticidas: Revista de Ecotoxicologia e Meio Ambiente, Curitiba, v. 13, p. 129-146, 2003. 
COSTA, M.C.G., MIOTTI, A.A., FERREIRA, T.O., ROMERO, R.E., 2016. Teor de nutrientes e viabilidade da bananicultura em Cambissolos com diferentes profundidades. Bragantia, Campinas, v. 75, n. 3, p. 335-343, maio 2016. Disponível em: $<$ http://www.scielo.br/scielo.php?script=sci arttext\&pid=S0006$87052016000300335 \& \operatorname{lng}=$ pt\&tlng=pt>. Acesso em 20 out. 2017.

DETMAN, A., CHOJNACKA, A, BŁASZCZYK, M., KAŹMIERCZAK, W., PIOTROWSKI, J., SIKORA, A. Biohydrogen and Biomethane (Biogas) Production in the Consecutive Stages of Anaerobic Digestion of Molasses. Polish Journal of Environmental Studies, v. 26, n. 3, p. 1023-1029, 2017.

DILALLO, R., ALBERTSON, O.E. Volatile acids by direct titration. Journal of water pollution control federation, v. 33, n. 4, p. 356-356, 1961.

DIMPE, K.M., NGILA, J.C., MABUBA, N., NOMGONGO, P.N. Evaluation of sample preparation methods for the detection of total metal content using inductively coupled plasma optical emission spectrometry (ICP-OES) in wastewater and sludge. Physics and Chemistry of the Earth, v. 76-78, p. 42-48, 2014.

DUBOIS, M., GILLES, K.A., HAMILTON, J.K., REBERS, P.A., SMITH, F. Colorimetric Method for Determination of Sugars and Related Substances. Analytical Chemistry, 28 (3), p. 350-356, 1956.

EHS - Environmental Health and Safety. Aqua Regia. Laboratory Safety Manual, Princeton University, 2017. Disponível em: <https://goo.gl/SUuksT>. Acesso em 15 out. 2017.

EMBRAPA - Empresa Brasileira de Pesquisa Agropecuária. Biorrefinarias. Agroenergia, p. 1-6, 2011. Disponível em: <https://goo.gl/wEp6ab>, Acesso em 17 out. 2017.

EMBRAPA - Empresa Brasileira de Pesquisa Agropecuária. Árvore do conhecimento, cana-de-açúcar. 2017. Disponível em: <https://goo.gl/Jrmypb>. Acesso em 20 out. 2017.

FERMOSO, F.G., BARTACEK, J., JANSEN, S., LENS, P.N.L. Metal supplementation to USAB bioreactors: from cell-metal interactions to full-scale application. Science of Total Environment, v. 407, n. 12, p. 3652-3667, 2009.

FERMOSO, F.G., BARTACEK, J., CHUNG, C., LENS, P. Supplementation of cobalt to UASB reactors by pulse dosing: $\mathrm{CoCl} 2$ versus CoEDTA2- pulses. Biochemical Engineering Journal, v. 42, n.2, p. 111-119, 2008.

FUESS, L.T., GARCIA, M.L. Qual o valor da vinhaça? Mitigação de impacto ambiental e recuperação de energia por meio da digestão anaeróbica. São Paulo, Cultura Acadêmica: Universidade Estadual Paulista, Pró-Reitoria de Graduação, 130 p., 2012.

FUESS, L.T., GARCIA, M.L. Implications of stillage land disposal: A critical review on the impacts of fertigation. Journal of Environmental Management, v. 145, p. 210-229, 2014.

FUESS, L.T. Potencial Contaminante e Energético da Vinhaça: Riscos de Contaminação ao Solo e Recursos Hídricos e Recuperação de Energia a Partir da Digestão Anaeróbia. Dissertação de Mestrado em Geociências e Meio Ambiente, Instituto de Geociências e Ciências Exatas do Câmpus de Rio Claro, Universidade Estadual Paulista Júlio de Mesquita Filho, 2013. 
HAN, W., BING WANG, B., ZHOU, Y., WANG, D., WANG, Y., YUE, L., LI, Y., REN, N. Fermentative hydrogen production from molasses wastewater in a continuous mixed immobilized sludge reactor. Bioresource Technology, v. 110, p. 219-223, 2012.

IEAa - Instituto de Economia Agrícola. Setor sucroenergético do Estado de São Paulo frente à crise econômica. 2016. Disponível em:

<http://www.iea.sp.gov.br/out/verTexto.php?codTexto=14060>. Acesso em 17 out. 2017.

IEAb - International Energy Agency. World Energy Outlook 2016 - Executive Summary. Paris, França, 2016. Disponível em: <https://goo.gl/Ctbdpa>. Acesso em 17 out. 2017.

IPCC- Intergovernmental Panel on Climate Change. Climate Change 2014 - Synthesis Report. 2014. Disponível em:

<https://www.ipcc.ch/site/assets/uploads/2018/02/AR5 SYR FINAL SPM.pdf>. Acesso em 16 out. 2017.

JANKE, L, LEITE, A.F., NIKOLAUSZ, M., SCHMIDT, T., LIEBETRAU, J., NELLES, M., STINNER, W. Biogas Production from Sugarcane Waste: Assessment on Kinetic Challenges for Process Designing. International Journal of Molecular Sciences, v. 16, p. 2068520703, 2015.

JANKE, L., LEITE, A.F., BATISTA, K., SILVA, W., NIKOLAUSZ, M., NELLE, M., STINNER, $W$. Enhancing biogas production from vinasse in sugarcane biorefineries: Effects of urea and trace elements supplementation on process performance and stability. Bioresource Technology, v. 217, p.10-20, 2016.

KRUG, F.J., ROCHA, F.R.P. (Orgs.). Métodos de preparo de amostras para análise elementar. São Paulo: EditSBQ, v. 1, p. 572, 2016.

LI, J., LI, B., ZHUA, G., RENA, N., BOA, L., HEA, J. Hydrogen production from diluted molasses by anaerobic hydrogen producing bacteria in an anaerobic baffled reactor (ABR). International Journal of Hydrogen Energy, n. 32, p. 3274 - 3283, 2007.

MORAES, B.S., JUNQUEIRA, T.L., PAVANELLO, L.G., CAVALLET, O., MANTELATTO, P.E., BONOMI, A., ZAIAT, M. Anaerobic digestion of vinasse from sugarcane biorefineries in Brazil from energy, environmental, and economic perspectives: Profit or expense? Applied Energy, v. 113, p. 825-835, 2014.

MUTTON, M.A., ROSSETTO, R., MUTTON, M.J.R. Utilização agrícola da vinhaça. In: CORTEZ, L.A.B. (Cord.). Bioetanol de cana-de-açúcar: P\&D para produtividade e sustentabilidade. São Paulo: Blucher: FAPESP, cap. 10, 2010.

NASA - National Aeronautics and Space Administration. Climate Change and Global Warming, Vital Signs of the Planet. EUA, 2017. Disponível em:

$<$ https://climate.nasa.gov/>. Acesso em 16 out. 2017.

OLIVEIRA, C.A. Digestão Anaeróbia Termofílica do Melaço de Cana-De-Açúcar em Reatores de Leito Fixo Estruturado de duas Fases e Fase Única para a Produção de Biogás. Dissertação de Mestrado em Ciências: Engenharia Hidráulica e Saneamento, Escola de Engenharia de São Carlos, Universidade de São Paulo, 2018.

PEREIRA, C.C., SOUZA, A.O., ORESTE, E.Q., VIEIRA, M.A., RIBEIRO, A. S. Evaluation of the use of a reflux system for sample preparation of processed fruit juices and subsequent determination of $\mathrm{Cr}, \mathrm{Cu}, \mathrm{K}, \mathrm{Mg}, \mathrm{Na}, \mathrm{Pb}$ and $\mathrm{Zn}$ by atomic spectrometry techniques. Food Chemistry, v. 240, p. 959-964, 2018. 
PERNA, V., CASTELLÓ, E., WENZEL, J., ZAMPOL, C., LIMA, D.M.F., BORZACCONI, L., VARESCHE, M.B., ZAIAT, M., ETCHEBEHERE, C. Hydrogen production in an upflow anaerobic packed bed reactor used to treat cheese whey. International Journal of Hydrogen Energy, 38 (1), p. 54-62, 2013.

PINHEIRO, A.C.A., LISBOA, M.T., RIBEIRO, A.S., NUNES, A.M., YAMASAKI, A. Avaliação da mineralização de arroz em sistema de refluxo para a determinação de $\mathrm{Cu}, \mathrm{Fe}, \mathrm{Mn}$ e Zn por FAAS. Química Nova, v. 37, n. 1, p. 6-9, 2014.

PUGLIANO, L.M., BARROS, V.G., DUDA, R.M., OLIVEIRA, R.A. Produção de biogás a partir da vinhaça e melaço utilizando reatores UASB. Ciência \& Tecnologia: Fatec-JB, Jaboticabal, v. 6, n. 1, p. 49-53, 2014. Disponível em: <https://goo.gl/JLwRms >. Acesso em 18 out. 2017.

RAJESHWARI, K., BALAKRISHNAN, M., KANSAL, A., LATA, K., KISHORE, V.V.N. State-ofthe-art anaerobic digestion technology for industrial wastewater treatment. Renewable and Sustainable Energy Reviews, v. 4, p. 135-156, 2000.

STANDARD, E. Characterization of Sludges - Determination of Trace Elements and Phosphorus - Aqua Regia Extraction Methods. European Committee for Standardization, EN 13346, Brussels, 2000.

THANH, P.M., KETHEESAN, B., YAN, Z., STUCKEY, D. Trace metal speciation and bioavailability in anaerobic digestion: A review. Biotechnology Advances, v. 34, p. 122-136, 2016.

TORQUATO, S.A., JESUS, K.R.E. Complementaridade da matriz energética brasileira: o potencial da cana-de-açúcar e seus co-produtos. Embrapa, Meio Ambiente, 2015. Disponível em: <https://goo.gl/9JQRgy>. Acesso em 17 out. 2017.

VALDUGA, E., VALÉRIO, A., TREICHEL, H., DI LUCCIO, M. Pré-tratamentos de melaço de cana-de-açúcar e água de maceração de milho para a bioprodução de carotenóides. Química. Nova, v. 30, n. 8, p. 1860-1866, 2007.

VON SPERLING, M. Introdução à qualidade das águas e ao tratamento de esgotos. Belo Horizonte: Departamento de Engenharia Sanitária e Ambiental - DESA, Universidade Federal de Minas Gerais. v. 1, 3. ed, 2005.

VON SPERLING, M. Lagoas de estabilização. Belo Horizonte: Departamento de Engenharia Sanitária e Ambiental - DESA, Universidade Federal de Minas Gerais, 134 p., 1996.

WILKIE, A.C., RIEDESEL, K.J., OWENS, J.M. Stillage characterization and anaerobic treatment of ethanol stillage from conventional and cellulosic feedstocks. Biomass and Bioenergy, Oxford, v. 19, n. 2, p. 63-102, 2000. 